\title{
Rapid immunodiagnostic assays for Mycobacterium Tuberculosis infection
}

\author{
Roba M. Talaat ${ }^{1 *}$, Gamal S. Radwan², Abdelaziz A. Mosaad ${ }^{3}$, Saleh A. Saleh ${ }^{4}$, Kalied Bassiouny $^{1}$ \\ ${ }^{1}$ Department of Molecular Biology, Genetic Engineering and Biotechnology Research Institute (GEBRI), Minufiya University, Egypt; \\ *Robamtalaat@yahoo.com \\ ${ }^{2}$ Department of Molecular Diagnosis, Genetic Engineering and Biotechnology Research Institute (GEBRI), Minufiya University, Egypt \\ ${ }^{3}$ Department of Microbiology, Faculty of Veterinary Medicine, Minufiya University, Egypt \\ ${ }^{4}$ Diagsera /VACSERA, Ministry of Health, Egypt
}

Received 24 November 2009; revised 6 January 2010; accepted 8 January 2010.

\begin{abstract}
Purpose: There is a need for a continued effort to develop rapid immunodiagnostic assays for tuberculosis (TB) infection with greater sensitivity and specificity that can be used in the field and in the laboratory and that can be formatted for use with multiple species. This would help to obtain definitive early diagnosis of TB. The present study was developed to determine the role of using early secreted antigenic target- 6 (ESAT-6) in immunodiagnosis of Mycobacterium tuberculosis. Methods: Serum samples were obtained from TB infected patients and normal healthy controls. Two rapid immunodiagnostic assays (Enzyme-linked immunosorbent assay (ELISA) and Immunoblotting) were performed. Results: The sensitivity of immunoblotting assay was $100 \%$; however, ESAT- 6 antigen was not able to discriminate between patients and normal controls. Application of direct ELISA using ESAT -6 antigen yielded $97.6 \%$ sensitivity and $75 \%$ specificity for the diagnosis of TB infection. Conclusion: In conclusion, the detection of antibodies against ESAT- 6 antigen in the sera of TB patients by direct ELISA could be used as a preliminary assay for diagnosis of human $M$. tuberculosis infection. A combination of the ELISA with either radiological or microscopic examination is required to overcome the low specificity of the assay for negative results.
\end{abstract}

Keywords: Tuberculosis; Diagnosis; ESAT-6; ELISA; Immunoblotting

\section{INTRODUCTION}

Tuberculosis (TB) is a global health problem with onethird of the world's population latently infected with Mycobacterium tuberculosis (MTB) and about 8 million cases of active disease occurring each year [1,2]. Due to the increasing numbers of persons with MTB in the last years, the worldwide dissemination of HIV infection, the strongest risk factor for MTB development, and the continual migration of people from areas with a high incidence of TB to highly industrialized countries, MTB is considered a global emergency [3-6]. In general, infection by MTB is controlled initially by host defenses, and the infection remains latent. However, latent TB infection has the potential to develop into active TB at any time. Because active TB is infectious and leads to the spread of MTB, rapid diagnosis and effective treatment of individuals with active $\mathrm{TB}$ are the most important component of TB control programs. Moreover, identification and treatment of persons with latent MTB infection who are at high risk of progressing to active disease, also may contribute to TB control [7].

Diagnosis of MTB based on clinical symptoms, chest radiography and sputum microscopy is sensitive but not specific [8]. Culture of bacteria is time-consuming, and usually the bacillus is not cultured [9], whereas nucleic acid-based methods such as polymerase chain reaction (PCR) are not consistently accurate enough for the diagnosis of smear-negative pulmonary TB [10]. The tuberculin skin test (TST), using purified protein derivative (PPD), is largely used for both diagnosis and screening. The greatest drawback of PPD is its broad cross-reactivity with antigens derived from several mycobacterial species, e.g., attenuated M. bovis bacillus Calmette-Guérin (BCG) used for vaccination, greatly decreasing the specificity of the TST [11,12]. Moreover, $10-25 \%$ of TB patients have a negative TST result, and this percentage increases up to $50 \%$ in patients with advanced disease or with immunodeficiency due to HIV coinfection [13,14]. MTB infection evokes a strong cell-mediated immune response, and detection of specific $\mathrm{T}$ cells might be a mean to detect infection [15-17]. Because of their ease of performance and cost effectiveness, serodiagnostic tests constitute a 
promise for early detection of TB. In fact, no serological test is commonly used in the diagnosis of TB [18].

In an effort to develop more accurate diagnostic tools, recent studies have led to the identification of the genomic segment BCG-region 1 (RD1), present in MTB but absent from all strains as well as almost all environmental mycobacteria [19-21]. Therefore, RD1 gene products offer the potential for the development of new diagnostic tests that may differentiate MTB infection from BCG vaccination as well as exposure to environmental mycobacteria. Two secretory, low molecular mass proteins, early secreted antigenic target 6 (ESAT-6) and culture filtrate protein 10 (CFP-10) have been identified as a product of this gene [22,23]. The antigens have already shown great potential for tuberculosis diagnosis [24,25]. Thus, the purpose of this study was to evaluate the diagnostic potential of two rapid immunodiagnostic assays (Immunoblotting and Enzyme-linked immunosorbent assay (ELISA) for the detection of $M$. tuberculosis infections using ESAT-6 antigen.

\section{MATERIALS AND METHODS}

\subsection{Human Sera}

Forty-two serum samples from patients with pulmonary tuberculosis were obtained from Mamora Chest Hospital (Alexandria, Egypt). They were diagnosed by a specialist using smear and/or sputum culture (Ziehl-Neelsen stain) [26] and confirmed by chest $\mathrm{X}$ ray. Sixteen control sera were collected from laboratory staffs (who never suffer from TB infection and did not get a vaccination). All investigations were done in accordance with the Ministry of Health, health and human Ethical Clearance Committee guidelines for clinical researches. Minufiya University local ethics committee approved the study protocol. All patients and controls agreed to be enrolled in this study.

\subsection{Sodium Dodecyl \\ Sulphate-Polyacrylamide Gel \\ Electrophoresis (SDS-PAGE)}

ESAT-6 antigen was kindly prepared and provided by Dr. William C. Davis (College of Veterinary Medicine, Washington State University, Pullman, WA, USA). Protein content was estimated by the Bradford method [27]. Antigen was analyzed by $12 \%$ SDS-PAGE using a discontinuous SDS-PAGE system [28] and stained with Coomassie brilliant blue (Sigma Chemical Co., St. Louis, MO, USA). The protein molecular weight standard was from invitrogen (Invitrogen Corporation Carlsbad, CA, USA).

\subsection{Immunoblotting}

ESAT-6 was subjected to $12 \%$ SDS-PAGE, electro- transferred onto $0.22 \mu \mathrm{m}$ nitrocellulose (NC) membrane (Bio-Rad Laboratories, Richmond, CA, USA) [29]. Electrophoretic transfer was accomplished in $1 \mathrm{~h}$ at $4^{\circ} \mathrm{C}$ with a constant 200V. After electrotransfer, the sheet was cut into $0.2 \mathrm{~cm}$ wide strips. The resolved bands on NC membrane were visualized with specific immunological detection as described by [29-30]. Briefly, the antigencontaining strips were incubated with sera of MTB infected patients diluted 1:50 in blocking buffer (phosphate-buffered saline (PBS) containing 5\% non-fat milk and $0.3 \%$ polyoxyethylene-20 (Tween-20) (Sigma) for $1 \mathrm{~h}$. All incubations were carried out at room temperature on an orbital shaker (Bellco, Vineland, NJ. USA). After incubation, the NC strips were washed with hot $\left(65^{\circ} \mathrm{C}\right)$ washing buffer (PBS/0.3\%Tween-20) and incubated for $1 \mathrm{~h}$ with peroxidase-labeled goat anti-human IgG (GAHGPOD) (kindly supplied by Dr. Victor Tsang, Division of Parasitic Diseases, Centers for Disease Control and Prevention, Atlanta, GA) diluted 1:1000. The strips were then washed 3 times with washing buffer and once with PBS only. Reactive bands were visualized by incubating the NC strips with freshly prepared substrate solution [50mg of 3, 3'-diaminobenzidine (DAB) and $5 \mu \mathrm{H}_{2} \mathrm{O}_{2}$ (30\%) dissolved in 50ml PBS, pH 7.2) (Sigma Chemical Company, St. Louis, MO]. Positive reaction bands appeared within $10 \mathrm{~min}$. The reaction was then stopped using distilled water.

\subsection{Enzyme Linked Immunosorbent Assay (ELISA)}

The ELISA was performed in 96 well flat bottomed microplates (Griener Labortechnik, Kremsmunster, Austria). The optimum antigen, serum and conjugate concentrations and the incubation times were determined by checkerboard titration. The wells were coated with $100 \mu \mathrm{l}$ of ESAT-6 diluted in PBS ( $\mathrm{pH}$ 7.2). The plates were incubated $1 \mathrm{~h}$ at $37^{\circ} \mathrm{C}$ then overnight at $4^{\circ} \mathrm{C}$. After one wash with PBS containing 0.05\% Tween-20 (PBS/Tw), $200 \mu \mathrm{l}$ of $5 \%$ non-fat milk diluted in $\mathrm{PBS} / \mathrm{Tw}$ were added to each well and incubated for $1.5 \mathrm{~h}$ at $37^{\circ} \mathrm{C}$. After one wash with PBS/Tw, tested TB-infected and normal healthy control sera $(100 \mu \mathrm{l} /$ well) diluted in dilution buffer (PBS/Tw containing $1 \%$ non fat milk) were added in duplicates and incubated at $37^{\circ} \mathrm{C}$ for $1.5 \mathrm{~h}$. At the end of the incubation period, plates were washed 3 times with $\mathrm{PBS} / \mathrm{Tw}$ and 100 $\mu \mathrm{l}$ GAHG-POD were incorporated to each well at dilution 1:1000 in dilution buffer. After 4 washes with PBS/Tw, $100 \mu \mathrm{l}$ of TMB (3, 3', 5, 5'-tetramethyl benzidine) and $\mathrm{H}_{2} \mathrm{O}_{2}(0.02 \%$ in citric acid buffer) substrate (Kirkegrd and Perry Lab, Caithersuburg, MY, USA) were added to each well. The incubation time for the substrate was $15 \mathrm{~min}$. at room temperature. The optical density was measured at 620nm using the UV-max ELISA plate reader (Molecular Devices Corp.). 


\subsection{Statistical Analysis}

Data are expressed as mean $\mathrm{OD} \pm \mathrm{SD}$ and were analyzed using the statistical software package for social science (SPSS). Suitable cutoff value for the ELISA was determined by receiver operating characteristics (ROC) analysis. Comparisons of patients and normal control groups were performed by the Student's t-test. The differences were considered significant if the probability was associated with $p<0.05$.

\section{RESULTS}

\subsection{Gel Electrophoresis}

ESAT-6 was subjected to SDS-PAGE followed by Comassie brilliant blue staining. As the results in Figure 1 showed, 2 bands were identified in ESAT-6 (7.1 and 6.5 kDa).

\subsection{Immunoblotting}

On screening of the TB infected sera, the immunoblotting assay sensitivity was $100 \%$ as all TB infected patients reacted with ESAT-6. However, the antigen was not able to discriminate between patients and normal controls (Figure 2).

\section{ELISA}

Each serum sample was tested for its reactivities against ESAT-6. Figure 3 showed the reactivity of TB infected sera and uninfected controls against ESAT-6. The mean absorbance value in the TB patients was $0.566 \pm 0.017$, significantly higher $(p<0.01)$ than that in normal control

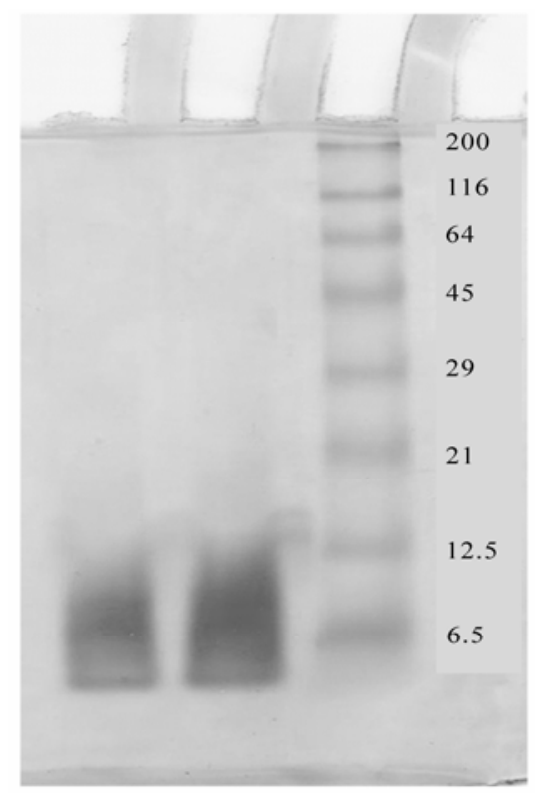

Figure 1. Coomassie blue stained $12 \%$ SDSPAGE gel of ESAT-6 antigen.

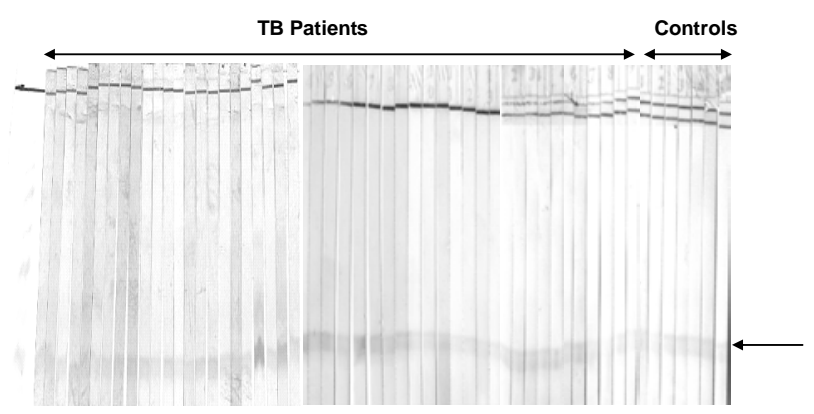

Figure 2. Western blot profile of $M$. tuberculosis patients and normal controls. ESAT $(0.1 \mu \mathrm{g} / \mathrm{mm})$ were separated by $12 \%$ SDS-PAGE, electrotransferred onto NC sheets, cut into $0.2 \mathrm{~cm}$ identical strips and reacted with patients and normal human serum (last 8 strips) diluted 1:50 in PBS/0.3\%Tween-20/5\% non-fat milk. Arrow pointed to the reactive band ( $\cong 6 \mathrm{kDa})$.

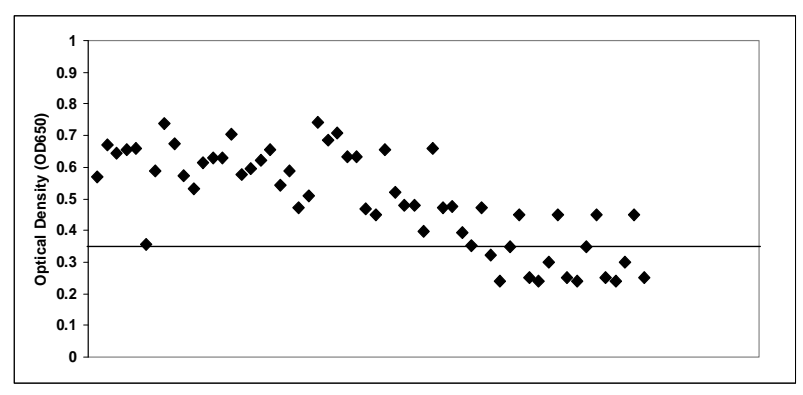

Figure 3. Reactivity of sera from $M$. tuberculosis infected patients against ESAT-6 antigen (as shown by direct ELISA).

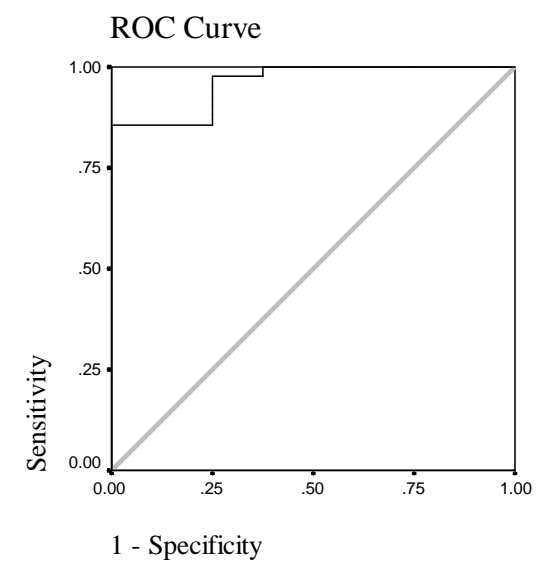

Figure 4. ROC curves for ELISA with ESAT-6.

group $(0.360 \pm 0.029)$. After ROC analysis (Figure 4), the area under the curve and standard error of the area under the curve were 0.961 (95\% confidence interval [CI], 0.918 to 1.005 ) and 0.022 , respectively. Among different cutoff values from the ROC analysis, a cutoff value of 0.351 was selected, as the sensitivity of $97.6 \%$ and specificity of $75 \%$ at the chosen cutoff was optimal for our ELISA. Out of 42 TB infected sera, only 1 serum sample showed a negative result at the cutoff value (1/42) (false negative). On the other hand, out of 16 normal 
controls, 4 serum samples showed a positive result at the cutoff value (4/16) (false positive).

\section{DISCUSSION}

Along with HIV and malaria, MTB has been declared a global enemy [31]. Delay in diagnosis is significant regarding not only disease prognosis at the individual level but also transmission within the community and the productive rate of TB epidemic [32,33]. An effective TB control program requires early diagnosis and immediate initiation of treatment. To control tuberculosis (TB), it is still necessary to find diagnostic methods that are both more rapid to carry out and more sensitive than traditional methods (smear and culture) but which are simpler and less expensive than the new molecular diagnostic tests that are based on the amplification of nucleic acids. Serological methods, which seem to be the ideal choice, are usually based on the detection of free soluble circulating antibodies against mycobacterial antigens. Thus, there is a need for a continued effort to develop rapid immunodiagnostic assays with greater sensitivity and specificity that can be used in the field and in the laboratory and that can be formatted for use with multiple species. Several secreted antigens have been characterized, and their utility for diagnostic testing as well as their attributes as vaccine components have been exploited [34-36].

An antibody detection test can be developed into several formats depending on the membrane, antigen(s) coating, and incubation technique. Common designs include ELISA and immunoblotting formats (commercial serological). TST has many drawbacks, such as the need for patients to return for test reading, as well as variability and subjectivity in test application and reading. Most importantly, TST has low specificity as PPD, the antigen used for the test, is a mixture of mycobacterial antigens also present in non tuberculous mycobacteria and in the BCG vaccine strains [11]. Although both assays (TST and ELISA) do not offer a good specificity in detection of $M$. tuberculosis infection, ELISA has many other advantages over the TST. Objective quantitative results can be obtained the day after blood sampling, and time spent on return visits to have the TST read is spared. Furthermore, since no antigen is injected, the problem of a booster affect on sequential skin tests is avoided. The test is simple to perform, and can be used even in countries with less-developed infrastructure.

ESAT-6 protein is secreted at an early or active phase of mycobacterial infection. It is virtually specific for $M$. tuberculosis complex representing a potential candidate for use in early detection as substitute or as improved skin test antigen [21-23,37-39]. Here in, we investigated the human antibody response against ESAT-6 antigen for the detection of $M$. tuberculosis infection using different immunoassays (immunoblotting and ELISA). Serial samples of sera collected from $M$. tuberculosis infected patients were subjected to our developed immunoblotting and ELISA to determine the serological response to ESAT6. Western blot analysis showed a reactive band at $\cong 6 \mathrm{kDa}$ with all serum samples. This may suggest that, using immunoblotting format assay, ESAT-6 antigen is not only recognized with individuals with TB infection but also with normal healthy controls. This result merely reflects a case of cross reaction that may returned to shared epitope identification afforded by this assay. Thus, our work showed that western blotting using ESAT antigen is not the suitable choice for diagnosis of $M$. tuberculosis infection and just used to support its diagnosis. On the other hand, application of ELISA has increased the sensitivity and specificity for diagnosis of $M$. tuberculosis infection to $97.6 \%$ and $75 \%$, respectively.

ESAT-6, for comparison, is broadly recognized early during disease in different species infected with $M$. tuberculosis or $M$. bovis [37,40,41] and this antigen is generally reported to trigger the release of high levels of IFN- $\gamma$ by sensitized peripheral blood mononuclear cells (PBMC) from TB patients [42,43]. This antigen discriminates TB patients from both BCG-vaccinated and M. avium patients and has therefore been suggested as a candidate for in vitro TB diagnosis $[42,43]$. The diagnostic potential of low molecular weight culture filtrate antigens (ESAT-6 and CFP-10) of $M$. tuberculosis has been reported in earlier studies [24,25,44]. It has been previously reported that subjects with latent TB infection may respond to ESAT-6 peptides and to the whole ESAT-6 protein [45-49]. Vincenti et al. [50] demonstrated that, patients with active TB recognized the whole ESAT6 protein or PPD. The lack of response in some TB patients may be due to their particular state of immune suppression [43-50].

Although serologic testing can detect specific antibodies to mycobacteria in serum and is attractive diagnostic method due to its ease of application, they present low sensitivity and specificity due to the great heterogeneity of the humoral response in patients with TB [51]. It is noteworthy that, in patients suffering from AIDS, in whom the number of $\mathrm{T}$ cells is decreased or even null, determining humoral response can be an invaluable tool in making an early diagnosis and gaining epidemiological control over TB [52]. Thus, even with 75\% specificity, getting 97.6\% sensitivity with ESAT-6 in ELISA format has improved the diagnostic potential of this antigen for TB diagnosis. Imaz et al. [18] suggested the use of multi-antigen cocktail to improve the diagnostic utility of the ELISA. The design of antigen combinations would achieve the high diagnostic accuracy of the assay.

In conclusion, this study offers the potential for developing relatively rapid assays (ELISA and western blotting) for detection of $M$. tuberculosis infection. We have tested the application of antibody reactivity against ESAT-6 antigens as a serodiagnostic marker. The results showed that the use of ESAT-6 improves the diagnosis's 
sensitivity and provide an ELISA as a simple method that could be applied in TB diagnosis. To overcome the low specificity of the assay, a combination of the ELISA with either radiological or microscopic examination is requireed for negative results.

\section{ACKNOWLEDGMENTS}

The current study was supported by Minufiya University and VACSERA. Authors would like to thank Dr. William C. Davis (Collage of Veterinary Medicine, Washington State University, Pullman, WA, USA) for his support by providing us with ESAT-6 antigen.

\section{REFERENCES}

[1] Brock, I., Weldingh, K., Leyten, E.M.S., Arend, S.M., Ravn, P. and Andersen, P. (2004) Specific T-Cell epitopes for immunoassay-based diagnosis of mycobacterium tuberculosis Infection. Journal of Clinical Microbiology, 42(6), 2379-2387.

[2] World Health Organization (WHO) (2007) Global tuberculosis control: Surveillance, planning, financing. WHO report. Geneva: World Health Organization. WHO/ HTM/ TB/2007.376.

[3] Di Perri, G., Cruciani, M., Danzi, M.C., Luzzati, R., De Checchi, G., Malena, M., Pizzighella, S., Mazzi, R., Solbiati, M., Concia, E., et al. (1989) Nosocomial epidemic of active tuberculosis among HIV infected patients. Lancet, 2, 1502-1504.

[4] Lucas, S. and Nelson, A.M. (1994) Pathogenesis of tuberculosis in human immunodeficiency virus-infected people. American Society for Microbiology Press, Washington, D.C., 29.

[5] Dye, C., Watt, C.J., Bleed, D.M., Hosseini, S.M. and Raviglione, M.C. (2005) Evolution of tuberculosis control and prospects for reducing tuberculosis incidence, prevalence, and deaths globally. Journal of the American Medical Association, 293, 2767-2775.

[6] Jasmer, R.M., Nahid, P. and Hopewell, P.C. (2002) Latent tuberculosis infection. New England Journal of Medicine, 347, 1860-1866.

[7] Bruchfeld, J., Aderaye, G., Palme, I.B., Bjorvatn, B., Britton, S., Feleke, Y., Kallenius, G. and Lindquist, L. (2002) Evaluation of outpatients with suspected pulmonary tuberculosis in a high HIV prevalence setting in Ethiopia: Clinical, diagnostic and epidemiological characteristics. Scandinavian Journal of Infectious Diseases, 34, 331-337.

[8] Anderson, D., Anderson, V., Pentland, L., Sawyer, S., Starr, M. and Johnson, P.D. (2000) Attention function in secondary school students receiving isoniazid prophylaxis for tuberculosis infection. Epidemiology and Infection, 124(1), 97- 101.

[9] Sarmiento, O.L., Weigle, K.A., Alexander, J., Weber, D.J. and Miller, W.C. (2003) Assessment by meta-analysis of PCR for diagnosis of smear-negative pulmonary tuberculosis. Journal of Clinical Microbiology, 41, 3233-3240.

[10] Chaparas, S.D., Maloney, C.J. and Hedrick, S.R. (1970) Specificity of tuberculins and antigens from various species of mycobacteria. American Review of Respiratory Diseases, 101, 74-83.

[11] Harboe, M. (1981) Antigens of PPD, old tuberculin, and autoclaved Mycobacterium bovis BCG studied by crossed immunoelectrophoresis. American Review of Respiratory Diseases, 124, 80-87.

[12] Huebner, R.E., Schein M.F. and Bass Jr.J. (1993) The tuberculin skin test. Clinical Infectious Diseases, 17, 968-975.

[13] Huebner, R.E., Schein, M.F., Hall, C.A. and Barnes, S.A. (1994) Delayed type hypersensitivity energy in human immunodeficiency virus-infected persons screened for infection with Mycobacterium tuberculosis. Clinical Infectious Diseases, 19, 26-32.

[14] Converse, P.J., Jones, S.L., Astemborski, J., Vlahov, D. and Graham, N.M. (1997) Comparison of a tuberculin interferon-gamma assay with the tuberculin skin test in high-risk adults: Effect of human immunodeficiency virus infection. Journal of Infectious Disease, 176, 144-150.

[15] Stenger, S. and Modlin, R.L. (1999) T-cell mediated immunity to Mycobacterium tuberculosis. Current Opinion in microbiology, 2, 89-93.

[16] Flynn, J.L. and Chan, J. (2001) Immunology of tuberculosis. Annual Review of Immunology, 19, 93-129.

[17] Delgado, J.C., Tsai, E.Y., Thim, S., Baena, A., Boussiotis, V.A., Reynes, J.M., Sath, S., Grosjean, P., Yunis, E.J. and Goldfeld, A.E. (2002) Antigen-specific and persistent tuberculin energy in a cohort of pulmonary tuberculosis patients from rural Cambodia. Proceedings of the $\mathrm{Na}$ tional Academy of Sciences, 99, 7576-7581.

[18] Imaz, M.S., Schmelling, M.F., Kaempfer, S., Spallek, R. and Singh, M. (2008) Serodiagnosis of tuberculosis: Specific detection of free and complex-dissociated antibodies anti-mycobacterium tuberculosis recombinant antigens. Brazilian Journal of Infectious Diseases, 12(3), 234-244.

[19] Mahairas, G.G., Sabo, P.J., Hickey, M.J., Singh, D.C. and Stover, C.K. (1996) Molecular analysis of genetic differences between Mycobacterium bovis BCG and virulent M. bovis. Journal of Bacteriology, 178, 1274-1282.

[20] Behr, M.A., Wilson, M.A., Gill, W.P., Salamon, H., Schoolnik, G.K., Rane, S. and Small, P.M. (1999) Comparative genomics of BCG vaccines by whole genome DNA microarray. Science, 284, 1520-1523.

[21] Arend, S.M., van Meijgaarden, K.E., de Boer, K., de Palou, E.C., van Soolingen, D., Ottenhoff, T.H. and van Dissel, J.T. (2002) Tuberculin skin testing and in vitro T cell responses to ESAT-6 and culture filtrate protein 10 after infection with mycobacterium marinum or M. kansasii. Journal of Infectious Disease, 186, 1797-1807.

[22] Sorensen, A.L., Nagai, S., Houen, G., Andersen, P. and Andersen, A.B. (1995). Purification and characterization of a low-molecular-mass T-cell antigen secreted by Mycobacterium tuberculosis. Infection and Immunity, 63, 1710-1717.

[23] Berthet, F.X., Rasmussen, P.B., Rosenkrands, I., Andersen, P. and Gicquel, B. (1998) A mycobacterium tuberculosis operon encoding ESAT-6 and a novel low-molecular-mass culture filtrate protein (CFP-10). Microbiology, 144 (Pt 11), 3195-3203.

[24] Arend, S.M., Andersen, P., van Meijgaarden, K.E., Skjot, R.L., Subronto, Y.W., van Dissel, J.T. and Ottenhoff, T.H. (2000) Detection of active tuberculosis infection by T cell responses to early-secreted antigenic target 6-kDa protein and culture filtrate protein 10. Journal of Infectious Disease, May, 181(5), 1850-1854.

[25] Ewer, K., Deeks, J., Alvarez, L., Bryant, G., Waller, S., Andersen, P., Monk, P. and Lalvani, A. (2003) Compari- 
son of T-cell-based assay with tuberculin skin test for diagnosis of Mycobacterium tuberculosis infection in a school tuberculosis outbreak. Lancet, 361, 1168-1173.

[26] Crookham, J. and Dapson, R. (1991) Hazardous chemicals in the histopathology laboratory, 2nd ED, Anatech.

[27] Bradford, M.M. (1976) A rapid and sensitive method for the quantitation of microgram quantities of protein utilizing the principle of protein dye binding. Analytical Biochemistry, 72, 248-254.

[28] Laemmli, U.K. (1970) Cleavage of structural proteins during the assembly of the head of bactriophage T4. Nature, 277, 680-685.

[29] Towbin, M., Staehelin, T. and Gordon, J. (1979) Electrophoretic transfer of proteins from polyacrylamide gels to nitrocellulose sheets: Procedure and applications. Proceedings of the National Academy of Sciences, 76, 4350-4354.

[30] Burnette, W.N. (1981) "Western Blotting”: Electrophoretic transfer of proteins from SDS-PAGE to unmodified nitrocellulose and radiographic detection with antibody and radioiodinated protein. Analytical Biochemistry, 112, 195-203.

[31] Storla, D.G., Yimer, S. and Bjune, G.A. (2008) A systematic review of delay in the diagnosis and treatment of tuberculosis. BMC Public Health, 8, 15.

[32] World Health Organization (WHO) (2005) Global tuberculosis control: Surveillance, planning, financing. WHO report. Geneva: World Health Organization. WHO/HTM/ $\mathrm{TB} / 2005.349$

[33] Bjune, G. (2005) Tuberculosis in the $21^{\text {st }}$ century: An emerging pandemic? Norsk Epidemiologi, 15(2), 133-139.

[34] Bothamley, G.H. (1995) Serological diagnosis of tuberculosis. European Respiratory Journal (Supplement 20), 676s-688s.

[35] Lodha, R. and Kabra, S.K. (2004) Newer diagnostic modalities for tuberculosis. Indian Journal of Pediatrics, 71(3), 221- 227.Links.

[36] Orme, I.M. (2006) Preclinical testing of new vaccines for tuberculosis: A comprehensive review. Vaccine, 9;24(1), 2-19.

[37] Pollock, J.M. and Andersen, P. (1997) The potential of the ESAT-6 antigen secreted by virulent mycobacteria for specific diagnosis of tuberculosis. Journal of Infectious Disease, 175, 1251-1254.

[38] Harboe, M., Oettinger T., Wiker H.G., Rosenkrands I. and Andersen P. (1996) Evidence for occurrence of the ESAT-6 protein in Mycobacterium tuberculosis and virulent Mycobacterium bovis and for its absence in Mycobacterium bovis BCG. Infection and Immunity, 64, 16-22.

[39] Geluk, A., van Meijgaarden, K.E., Franken, K.L., Subronto, Y.W., Wieles, B., Arend, S.M., Sampaio, E.P., de Boer, T., Faber, W.R., Naafs, B. and Ottenhoff, T.H. (2002) Identification and characterization of the ESAT-6 homologue of Mycobacterium leprae and T-cell cross-reactivity with Mycobacterium tuberculosis. Infection and Immunity, 70, 2544-2548.

[40] Andersen, P., Andersen, A.B., Sorensen, A.L. and Nagai, S. (1995) Recall of long-lived immunity to Mycobacterium tuberculosis infection in mice. Journal of Immunology, 154, 3359-3372.

[41] Brandt, L., Oettinger, T., Holm, A. and Andersen, P. (1996) Key epitopes on the ESAT- 6 antigen recognized in mice during the recall of protective immunity to Mycobacterium tuberculosis. Journal of Immunology, 157, 3527-
3533.

[42] Ulrichs, T., Munk, M. E., Mollenkopf, H., Behr-Perst, S., Colangeli, R., Gennaro, M. L. and Kaufmann, S.H. (1998) Differential T cell responses to Mycobacterium tuberculosis ESAT-6 in tuberculosis patients and healthy donors. European Journal of Immunology, 28, 3949-3958.

[43] Ravn, P., Demissie, A., Eguale, T., Wondwosson, H., Lein, D., Amoudy, H.A., Mustafa, A.S., Jensen, A.K., Holm, A., Rosenkrands, I., Oftung, F., Olobo, J., von Reyn, F. and Andersen, P. (1999) Human T cell responses to the ESAT -6 antigen from Mycobacterium tuberculosis. Journal of Infectious Disease, 179(3), 637-645.

[44] Laurens, A., Van Pinxteren, H., Ravn, P., Agger, E.M., Pollock, J. and Andersen, P. (2000) Diagnosis of tuberculosis based on the two specific antigens ESAT-6 and CFP10. Clinical and Diagnostic Laboratory Immunology, 7(2), 155-160.

[45] Lalvani, A., Pathan, A.A., Durkan, H., Wilkinson, K.A., Whelan, A., Deeks, J.J., Reece, W.H., Latif, M., Pasvol, G. and Hill, A.V. (2001a) Enhanced contact tracing and spatial tracking of Mycobacterium tuberculosis infection by enumeration of antigen-specific T cells. Lancet, 357, 2017-2021.

[46] Lalvani, A., Nagvenkar, P., Udwadia, Z., Pathan, A.A., Wilkinson, K.A., Shastri, J.S., Ewer, K., Hill, A.V., Mehta, A. and Rodrigues, C. (2001b) Enumeration of T cells specific for RD1-encoded antigens suggests a high prevalence of latent Mycobacterium tuberculosis infe- ction in healthy urban Indians. Journal of Bacteriology, 183, 469-477.

[47] Lalvani, A., Pathan, A.A., McShane, H., Wilkinson, R.J., Latif, M., Conlon, C.P., Pasvol, G. and Hill, A.V. (2001c) Rapid detection of Mycobacterium tuberculosis infection by enumeration of antigen-specific $\mathrm{T}$ cells. American Journal of Respiratory and Critical Care Medicine, 163, 824-828.

[48] Pathan, A.A., Wilkinson, K.A., Klenerman, P., McShane, H., Davidson, R.N., Pasvol, G., Hill, A.V. and Lalvani, A. (2001) Direct ex vivo analysis of antigen-specific IFN- $\gamma$-secreting CD4 T cells in Mycobacterium tuberculosis-infected individuals: Association with clinical disease state and effect of treatment. Journal of Immunology, 167, 5217-5225.

[49] Chapman, A.L., Munkanta, M., Wilkinson, K.A., Pathan, A.A., Ewer, K., Ayles, H., Reece, W.H., Mwinga, A. Godfrey-Faussett, P. and Lalvani, A. (2002) Rapid detection of active and latent tuberculosis infection in HIV-positive individuals by enumeration of Mycobacterium tuberculosis-specific T cells. AIDS, 16, 2285-2293.

[50] Vincenti, D., Carrara, S., De Mori, P., Pucillo, L.P., Petrosillo, N., Palmieri, F., Armignacco, O., Ippolito, G., Girardi, E., Amicosante, M. and Goletti1, D. (2003) Identification of early secretory antigen target- 6 epitopes for the immunodiagnosis of active tuberculosis. Molecular Mmedicine, 9(3), 105-111.

[51] Lyashchenko, K., Colangeli, R., Houde, M., Al Jahdali, H., Menzies, D. and Gennaro, M.L. (1998) Heterogeneous antibody responses in tuberculosis. Infection and Immunology, 66(8), 3936-3940.

[52] Teixeira, H.C., Abramo, C. and Munk, M.E. (2007) Immunological diagnosis of tuberculosis: Problems and strategies for success. Jornal Brasileiro de Pneumologia, 33(3), 323-334. 